\title{
IDENTIFICATION AND DETECTION OF BIOFILM PRODUCING STAPHYLOCOCCUS AUREUS AND ITS ANTIBIOGRAM ACTIVITIES
}

\author{
SAPANA SHARMA ${ }^{1}$, UPASHANA BHANDARI ${ }^{2}$, YOGESH OLI ${ }^{1}$, GANESH BHANDARI ${ }^{2}$, SUNITA BISTA ${ }^{2}$, GANGA GC $^{1}$, \\ BASUDHA SHRESTHA ${ }^{3}$, NETRA LAL BHANDARI ${ }^{2 *}$
}

${ }^{1}$ Department of Microbiology, Tri-Chandra Multiple Campus, Tribhuvan University, Kathmandu, Nepal. ${ }^{2}$ Department of Chemistry, Tri-Chandra Multiple Campus, Tribhuvan University, Kathmandu, Nepal. ${ }^{3}$ Department of Microbiology, Kathmandu Model Hospital, Kathmandu, Nepal. Email: netra.tu.edu@gmail.com

Received: 01 January 2021, Revised and Accepted: 12 February 2021

ABSTRACT

Objectives: The main aim of this work is to determine the antibiogram profile of biofilm-producing Staphylococcus aureus from various clinical specimens of the patients.

Methods: Various bacterial cultures of non-repeated clinical specimens from a total of 3388 patients were determined using standard microbiological and biochemical methods.

Results: Out of 3388 only 604 (17.02\%) displayed growth positive. A total of 65 (51.58\%) S. aureus isolates were recovered, 25 (38.46\%) were identified as methicillin-resistant $S$. aureus (MRSA) by Cefoxitin $(30 \mu \mathrm{g})$ disk diffusion technique, of which majority were from pus/wound swab 22 (37.29\%). The antibiogram of the isolates was analyzed by Kirby-Bauer disk diffusion technique analyzing Linezolid to be the most effective drug with susceptibility of $100 \%$ to both MRSA and methicillin-sensitive $S$. aureus, followed by vancomycin, tigecycline, and tetracycline. In vitro biofilm production by tissue culture plate (TCP) and Congo red agar method detected 52 (80\%) and 25 (38.46\%) as biofilm producers, respectively. TCP identified 2 (3.07\%), 7 (10.76\%), and 44 (67.69\%) as strongly, moderately, and weakly adherent. About 30.7\% of MRSA obtained were positive biofilm producers. The minimum inhibitory concentration value of Oxacillin for $S$. aureus by agar dilution method ranged from $0.025 \mu \mathrm{g} / \mathrm{mL}$ to $128 \mu \mathrm{g} / \mathrm{mL}$.

Conclusion: This study shows that biofilm production was more in methicillin-resistant strains and displayed a high degree of resistance to almost all groups of antibiotics.

Keywords: Methicillin-resistant Staphylococcus aureus, Methicillin-sensitive Staphylococcus aureus, Biofilm, Kirby-Bauer disk diffusion, Tissue culture plate, Minimum inhibitory concentration.

(C) 2021 The Authors. Published by Innovare Academic Sciences Pvt Ltd. This is an open access article under the CC BY license (http://creativecommons.org/ licenses/by/4.0/) DOI: http://dx.doi.org/10.22159/ajpcr.2021v14i4.40728. Journal homepage: https://innovareacademics.in/journals/index.php/ajpcr

\section{INTRODUCTION}

Staphylococcus aureus, a Gram-positive, round-shaped bacterium about $0.8-1.0 \mu \mathrm{m}$ in diameter, a member of the family Micrococcaceae, frequently found in the upper respiratory and on the skin [1]. It is also a pathogen armed with virulence factors including pore-forming toxins, superantigens, phagocytosis inhibitors, biofilm-forming capacity, and evasion of the host immune system $[2,3]$.

A biofilm comprises any syntrophic consortium of microorganisms in which a multilayered cell cluster is embedded in the matrix of extracellular polysaccharide (slime) which facilitate the adherence of these organisms to the medial surface and protect them from host immune system and antimicrobial therapy [4]. A Dutch researcher, Antoni Van Leeuwenhoek observed an animalcule first time on the surface of a tooth using a simple microscope which was considered a biofilm discovery. The biofilm formation involves the production of a polysaccharide intracellular adhesion along with several surface proteins including biofilm-associated protein, $S$. aureus surface protein $\mathrm{G}$, and fibronectin-binding proteins $[5,6]$.

Infections due to multiple drug-resistant strains are becoming more critical due to their capacity to produce biofilm. The incidents of community-acquired and hospital-acquired $S$. aureus have been augmenting with the increasing emergence of a drug-resistant strain called methicillin-resistant S. aureus (MRSA). The presence of the mecA gene located on the cassette chromosome in S. aureus (SCC mec) is responsible for methicillin-resistant. MRSA has been considered a global public health threat, causing high nosocomial infections in patients' intensive care units (ICUs), leading to a higher mortality rate [7]. Biofilm formation by MRSA has more resistance to the host immune response and more tolerant to antimicrobials. MRSA was first identified in 1961 in England [8]. The percentage of hospital isolation MRSA in the developed countries has increased from $2 \%$ in the 1970 s to $30 \%$ in the 1990 s [9].

In the UK $44 \%$ of $S$. aureus isolated from the health-care system are MRSA and in Japan $60-70 \%$ of $S$. aureus are MRSA in inpatients. In Nepal, the prevalence of MRSA shows an increasing trend, 29.1-68\%. The MRSA infection rate reported all over Nepal was $43.1 \%$, which has turned out to be a perilous situation in Nepal [10].

It is now well documented that biofilms are notoriously difficult to eradicate and are often resistant to systemic antibiotic therapy [11]. The risk factor contributes to MRSA infection and colonization include excessive use of antibiotics, prolonged hospitalization especially in ICUs, intravascular catheterization, and immune-compromised states [12,13]. This work aims to isolate $S$. aureus from different clinical specimens for determining its antibiotic susceptibility, and rate of MRSA and methicillin-sensitive S. aureus (MSSA). Further, it helps, to determine biofilm-producing $S$. aureus to compare its antibiotic susceptibility pattern using different assay techniques.

\section{METHODS}

Study design and sample size

A descriptive cross-sectional hospital-based study was conducted from September 16, 2016, to April 15, 2017, AD at the laboratory of 
Kathmandu Model Hospital, Kathmandu, Nepal. A total of 3388 different clinical samples were collected from the inpatients and outpatients.

Samples sized 3388 comprising blood (804), body fluid (116), bone marrow (2), invasive devices (37), pus/wound (230), semen (7), sputum (412), stool (17), swab (22), throat swab (14), tissue (19), and urine (1708), were cultured for the isolation of $S$. aureus and methicillin resistance.

\section{Collection, transportation, and culture of the specimen}

All clinical samples were collected in a sterile, dry container, transported to the laboratory, and processed as soon as possible. In general, two samples were taken from each patient, one for Gram staining and the other for culture [14].

The received specimens in the laboratory were immediately cultured on blood agar, MacConkey agar, and chocolate agar based on the nature of the samples. The inoculums on the plate were streaked with a sterile inoculating loop to obtain discrete colonies which were then incubated at $37^{\circ} \mathrm{C}$ for $24 \mathrm{~h}$ for aerobic culture [15]. The culture of $S$. aureus in mannitol salt agar is shown in Fig. 1.

\section{Antibiotic susceptibility test}

The growth of colonies was identified based on morphology, Gram staining, and biochemical tests. Routine conventional laboratory techniques including Gram staining, catalase, oxidase, slide and tube coagulase test, and DNase test were carried out.

Kirby-Bauer disk diffusion method using Mueller-Hinton agar (MHA) was employed for antibiotic susceptibility test of the $S$. aureus as recommended by clinical laboratory standard institute [16]. Pure colonies of organisms were transferred in sterile nutrient broth to make the bacterial suspensions comparative with 0.5 McFarland standard. It was inoculated using a sterile swab into each Petri dishes containing MHA and is allowed to stand for $30 \mathrm{~min}$ for pre-diffusion of inoculated organisms in which antibiotics were needed. The commercial antibiotics discs and concentration used were ciprofloxacin $(5 \mu \mathrm{g})$, penicillin $\mathrm{G}$ $(10 \mu \mathrm{g})$, gentamicin $(30 \mu \mathrm{g})$, cotrimoxazole $(25 \mu \mathrm{g})$, cefoxitin $(30 \mu \mathrm{g})$, erythromycin $(30 \mu \mathrm{g})$, chloramphenicol $(30 \mu \mathrm{g})$, amoxicillin $(10 \mu \mathrm{g})$, vancomycin $(30 \mu \mathrm{g})$, amoxiclav (30 $\mu \mathrm{g})$, linezolid (30 $\mu \mathrm{g})$, cephalexin $(30 \mu \mathrm{g})$, cloxacillin $(5 \mu \mathrm{g})$, tetracycline $(30 \mu \mathrm{g})$, and tigecycline $(30 \mu \mathrm{g})$. The diameter of the zone of inhibition was measured and the results were interpreted. The MRSA in antibiotics is shown in Fig. 2.

\section{Screening of MRSA}

Cefoxitin $(30 \mu \mathrm{g})$ using modified Kirby-Bauer disk diffusion method was used for the screening of methicillin resistance $S$. aureus. The isolated colonies were prepared in nutrient broth suspension matched with turbidity $0.5 \mathrm{McF}$ arland. A sterile cotton swab was taken and left for $10 \mathrm{~min}$ for the diffusion of the antibiotic. The plate was incubated at

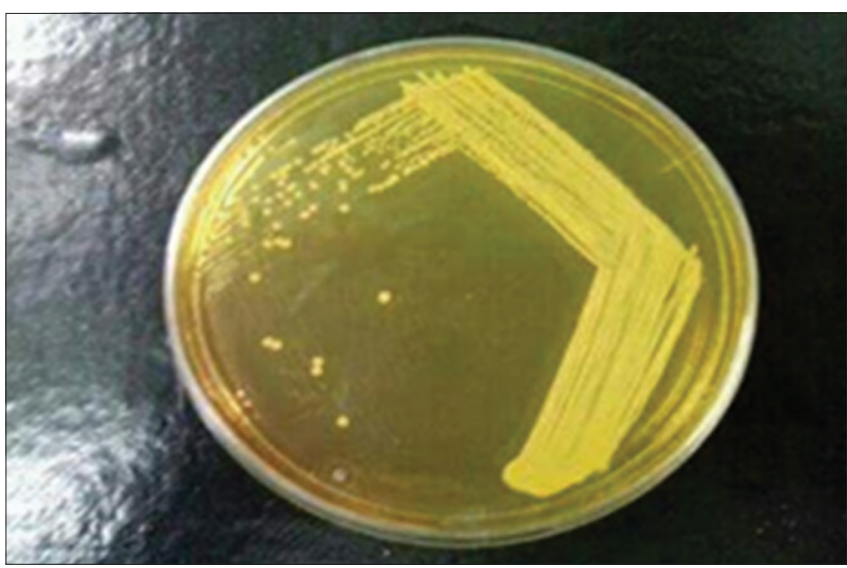

Fig. 1: Photograph of pure culture of Staphylococcus aureus in Mannitol salt agar $37^{\circ} \mathrm{C}$ for $24 \mathrm{~h}$ and zone of diameter was measured and MRSA $(<21 \mathrm{~mm})$ was confirmed.

Minimum inhibitory concentration (MIC) of oxacillin by Agar dilution method

Agar dilution method following CLSI guidelines (2014) was employed in determining MIC of oxacillin, ranging dilution of oxacillin from $0.125 \mu \mathrm{g} / \mathrm{mL}$ to $128 \mu \mathrm{g} / \mathrm{mL}$

\section{Screening of biofilm production}

Screening of biofilm was enumerated using two different assay methods; the Congo red agar (CRA) and tissue culture plate (TCP) methods.

In CRA method, $S$. aureus was inoculated in CRA comprising brain heart infusion (BHI) broth supplemented with $2 \%$ sucrose and Congo red. It was incubated at $37^{\circ} \mathrm{C}$ for $24 \mathrm{~h}$ and the representative plate is presented in Fig. 3. The film produced was observed and interpreted; a positive result indicated black color colonies with a dry crystalline consistency.

In the TCP method, the bacterial suspension was grown on tryptic soya broth (TSB) supplemented with 1\% glucose and then diluted to 1:100. The $200 \mu \mathrm{L}$ of this diluted inoculum poured into the wells of sterile flat bottomed 96 well-polystyrene TCPs and $200 \mu \mathrm{L}$ of TSB supplemented with $1 \%$ glucose used as a negative control. The assay plates were covered with an adhesive foil lid which increased biofilm formation by creating an environment with reduced oxygen tension. After incubation, the optical density (OD) of each well was measured using a multi-well plate reader to quantify the growth. The liquid culture from each well was removed by washing each well 3-4 times with deionized water while taking care to preserve the structure of the biofilm located on the bottom of each good assay. The washed plates were incubated at $60^{\circ} \mathrm{C}$ for at least $60 \mathrm{~min}$. After fixing the biofilm, staining was performed. The

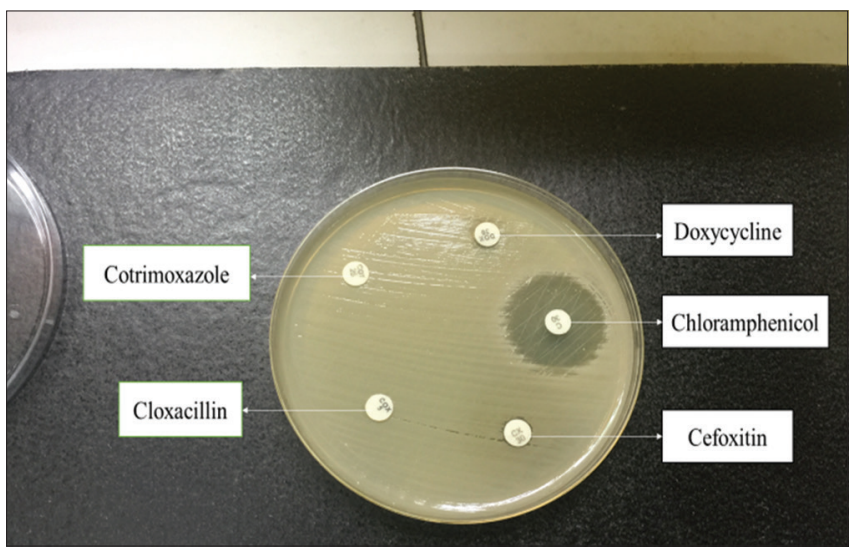

Fig. 2: Photograph of methicillin-resistant Staphylococcus aureus

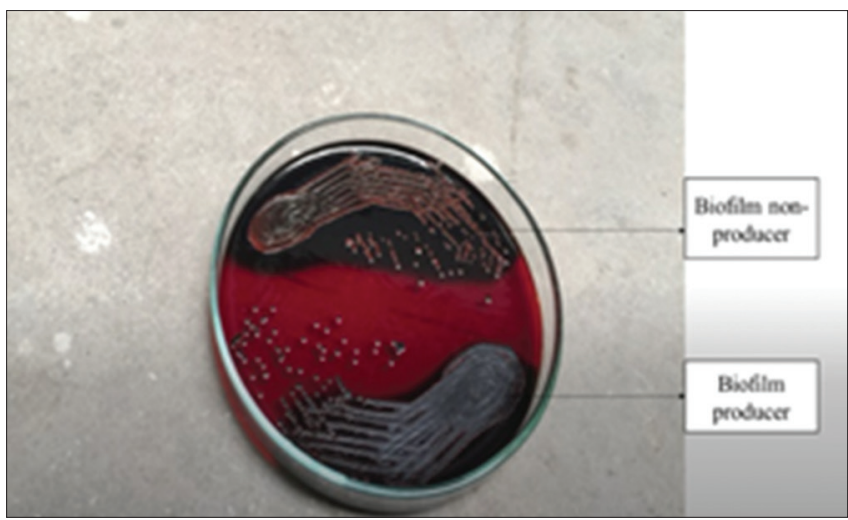

Fig. 3: Crystalline black colonies as biofilm producer and brown colonies as biofilm non-producer on Congo red agar 
observed biofilm could be detected and quantified using various stains. $50 \mu \mathrm{L} 0.1 \% \mathrm{CV}$ was added to each well and allowed at least $15 \mathrm{~min}$ for staining since biofilms were heat-fixed at $60^{\circ} \mathrm{C}$. After washing, $30 \%$ acetic acid was added to each well and measured the OD $570[17,18]$. The tissue plate culture is shown in Fig. 4.

The OD of the observed biofilm was calculated usitxng the standard protocol mentioned in the literature (Moghadam et al., 2014).

Cut off $\mathrm{OD}=3$ standard deviation + mean

ODs $\leq$ ODc $=$ no biofilm producer

ODc $\leq$ ODs $\leq 2 \times$ ODc $=$ weak biofilm producer

$2 \times$ ODc $=$ ODs $=4 \times$ ODc $=$ moderately biofilm producer

$4 \times \mathrm{ODc}=\mathrm{ODc}=$ strong biofilm producer

(ODc: Optical density of control, ODs: Optical density of sample).

\section{Quality contro}

The quality of each test was ensured following standard protocol. The temperature of the incubator and refrigerator was monitored every day. The media and reagents after preparation were tested in each batch, labeled properly, and stored in proper condition. The purity of plates

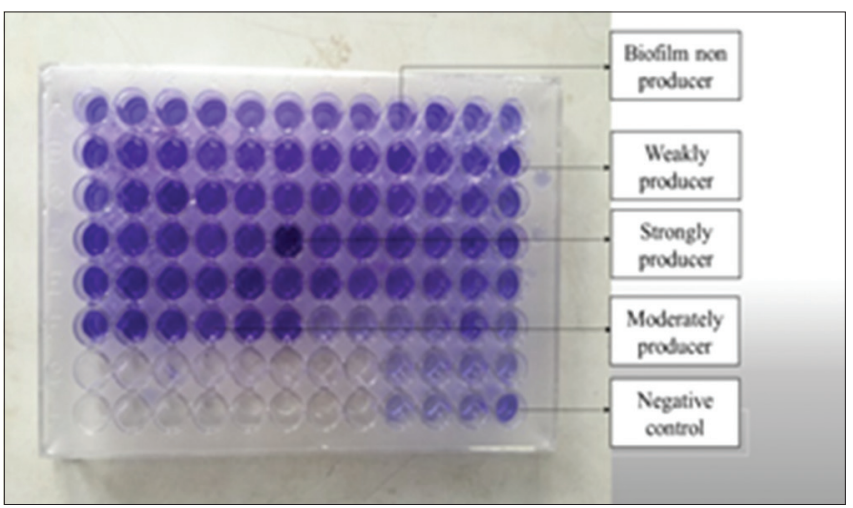

Fig. 4: Photographs showing the produced biofilm by tissue culture plate method (F6= ATCC Staphylococcus aureus; H12= Negative control)

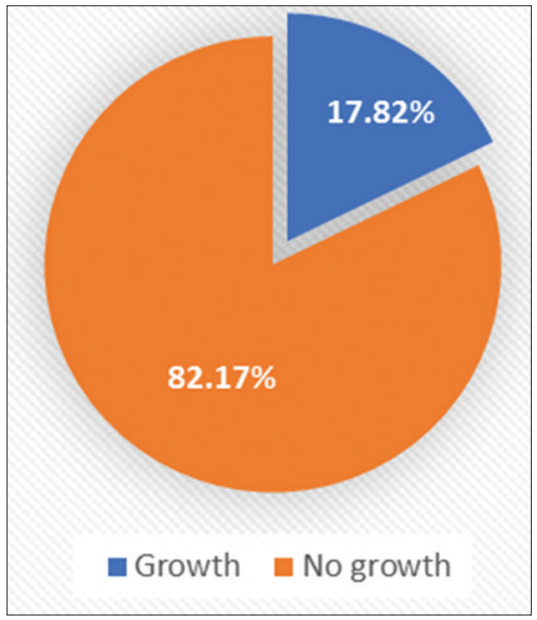

Fig. 5: Growth pattern of microbial isolates from clinical specimens of culture and the biochemical test was performed to ensure that the test was completed in aseptic condition. The plates were incubated at $37^{\circ} \mathrm{C}$ overnight.

It was ensured that only pure culture was used for identification and antibiotic susceptibility testing of organisms. The sterility of CRA was determined by incubating one plate of each batch in an incubator for $24 \mathrm{~h}$.

\section{Statistical analysis}

All the raw data obtained were statistically evaluated using a computerbased software program, Statistical Package for the Social Sciences (SPSS) version 20 software packages. A Chi-square test was used to analyze the association between two variables and $p<0.05$ was considered statistically significant.

\section{RESULTS AND DISCUSSION}

Among a total of 3388 samples, 604 (17.82\%) were culture positive and the rest $2784(82.17 \%)$ showed no growth as presented in (Fig. 5). Out of total specimens, 2817 were from outpatients, of which $462(19.6 \%)$ showed positive growth and $2355(82.02 \%)$ were culture negative. Furthermore, 571 samples were from the inpatient department, of which 142 (24.8\%) were growth positive and the rest 429 (75.13\%) showed no growth.

\section{Bacterial growth in clinical specimens}

Out of 604 culture-positive specimens, 576 (95.60\%) showed monomicrobial growth, of which 449 (74.33\%) were Gram-negative bacteria whereas $126(20.86 \%)$ were Gram-positive and $1(0.16 \%)$ were found to be yeast (Candida albicans). Furthermore, 28 (4.63\%) showed polymicrobial growth.

Among 126 isolates, 106 (86.50\%) were Staphylococci, out of which 65 $(51.58 \%)$ were detected as S. aureus and $44(34.92 \%)$ as CoNS. The rest $17(13.49 \%)$ were detected to be non-staphylococcal growth which is shown in Table 1.

Distribution frequency of $S$. aureus in diverse clinical samples The study included different clinical specimens such as blood, invasive devices, pus/wound swab, swab, tissue, urine, and stool. The $S$. aureus obtained from a total of 604 growth positive specimens were 65 in number, of which the majority were from pus/wound swab as shown in Table 2.

Distribution frequency of $S$. aureus concerning age and gender of patients

Among 65 isolates of S. aureus, 41 (63.07\%) and 24 (36.92\%) were obtained from male and female patients, respectively. The maximum number of patients infected belonged to the age group of 21-30 years, followed by the age group of 31-40 years. Furthermore, the number of patients infected belonged to the age group 81-90 years as shown in Table 3 .

\section{Antibiotic susceptibility pattern of $S$. aureus}

All $S$. aureus obtained from different clinical samples were tested for antibiotic susceptibility according to CLSI (2014) by modified KirbyBauer's Disk diffusion techniques. Linezolid was found to be the most effective drug with susceptibility of $100 \%$ toward both MRSA and MSSA represented in Table 4.

\section{Rate of MSSA}

Among a total of $65 \mathrm{~S}$. aureus isolates on performing disk diffusion method, 25 (38.46\%) were identified to be MRSA by cefoxitin $(30 \mu \mathrm{g})$ and the remaining 40 (61.54\%) to be MSSA as shown in Fig. 6.

Table 1: Growth of Gram-positive bacteria among different clinical specimens

\begin{tabular}{llllll}
\hline Growth positive & \multicolumn{2}{l}{ Staphylococcal growth } & \multirow{2}{*}{ Non-Staphylococcal growth } & Total \\
\cline { 2 - 4 } & CoNS & Staphylococcus aureus & Total & & \\
\hline Frequency (\%) & $44(34.92)$ & $65(51.58)$ & $109(86.50)$ & $17(13.49)$ & $126(100)$ \\
\hline
\end{tabular}


Disk diffusion method on 65 isolates of S. aureus identified 25 (38.46\%) and $40(61.53 \%)$ to be MRSA and MSSA, respectively. Pus/wound swab displayed a large number of MRSA, followed by blood, invasive devices, and tissue to the least as demonstrated in Table 5.

Distribution frequency of MRSA and MSSA in outpatients and inpatients

Out of 25 MRSA, 11 of them isolate confined from inpatients and 14 from outpatients. The association between MRSA occurrences in inpatients was statistically significant $(p<0.05)$, which demonstrated the fact that the chance of finding MRSA in admitted patients was high as compared to the outpatients as shown in Table 6.

Among 14 MRSA isolates obtained from the outpatients, 12 of them were male and two were female. Furthermore, 11 MRSA isolates were from inpatients, of which seven were male and four females. There was no statistical significance as shown in Table 7.

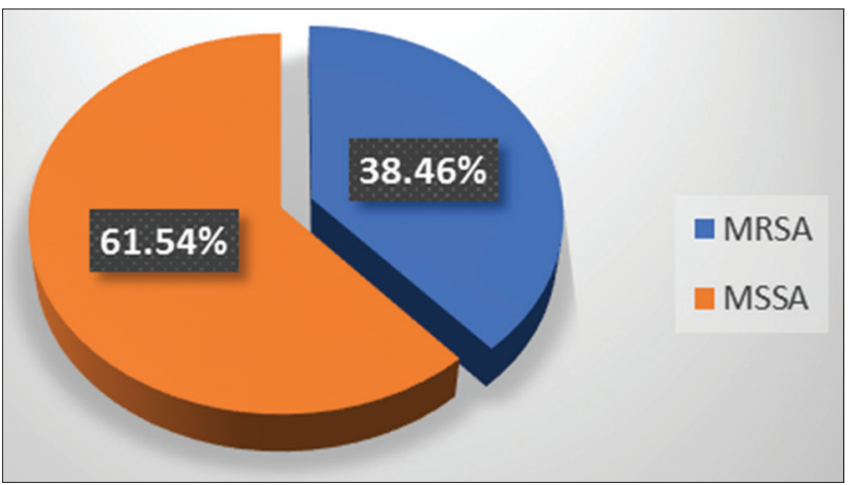

Fig. 6: Pie chart showing rate of MRSA and MSSA

Table 2: Distribution frequency of $S$. aureus in variable clinical samples

\begin{tabular}{llll}
\hline $\begin{array}{l}\text { Clinical } \\
\text { specimens }\end{array}$ & $\begin{array}{l}\text { Number of } \\
\text { growth positive }\end{array}$ & $\begin{array}{l}\text { Number of } \\
\text { S. aureus }\end{array}$ & Percentage \\
\hline Blood & 70 & 1 & 1.43 \\
Body fluid & 7 & - & - \\
Bone marrow & - & - & - \\
Invasive devices & 15 & 1 & 6.67 \\
Pus/wound swab & 148 & 59 & 39.87 \\
Semen & - & - & - \\
Sputum & 50 & - & - \\
Swab & 10 & 3 & 30.0 \\
Throat swab & 1 & - & - \\
Tissue & 12 & 1 & 8.34 \\
Urine & 291 & - & - \\
Total & 604 & 65 & 86.31 \\
\hline
\end{tabular}

S. aureus: Staphylococcus aureus

Table 3: Age- and gender-wise distribution frequency of Staphylococcus aureus infected patients

\begin{tabular}{llll}
\hline Age of patients (years) & Male & Female & Frequency (\%) \\
\hline$\leq 10$ & 6 & 3 & $9(13.82)$ \\
$11-20$ & 3 & 2 & $5(7.69)$ \\
$21-30$ & 11 & 6 & $17(26.15)$ \\
$31-40$ & 9 & 5 & $14(21.5)$ \\
$41-50$ & 3 & 3 & $6(9.23)$ \\
$51-60$ & 5 & 2 & $7(10.76)$ \\
$61-70$ & 2 & 1 & $3(4.62)$ \\
$71-80$ & 1 & 2 & $3(4.62)$ \\
$81-90$ & 1 & 0 & $1(1.5)$ \\
Total $(\%)$ & $41(63.07)$ & $24(36.92)$ & $65(100)$ \\
\hline
\end{tabular}

Disclosure of in vitro biofilm formation by TCP and CRA method A total of $65 \mathrm{~S}$. aureus isolates undergoing CRA method demonstrated $25(38.46 \%)$ as biofilm producer and the rest $45(61.53 \%)$ as a nonbiofilm producer. Similarly, the TCP method disclosed 52 (80\%) to be positive biofilm producers, of which 43 (66.15\%), 7 (10.76\%), and $2(3.07 \%)$ as weak, moderate, and strong adherent, respectively.

Table 4: AST pattern of Staphylococcus aureus from different clinical specimens

\begin{tabular}{llllll}
\hline \multirow{2}{*}{ Antibiotics used } & \multicolumn{2}{l}{ MRSA (n=25) } & & \multicolumn{2}{c}{ MSSA (n=40) } \\
\cline { 2 - 3 } \cline { 5 - 6 } & $\mathbf{R}(\%)$ & $\mathbf{S}(\%)$ & & $\mathbf{R}(\%)$ & $\mathbf{S}(\%)$ \\
\hline Penicillin-G & $25(100)$ & - & & $36(90)$ & $4(10)$ \\
Amoxicillin & $25(100)$ & - & & $36(90)$ & $4(10)$ \\
Amoxiclav & $18(72)$ & $7(28)$ & & $25(62.5)$ & $15(37.5)$ \\
Cefoxitin & $25(100)$ & - & & - & $40(100)$ \\
Cephalexin & $6(24)$ & $19(76)$ & & $1(2.5)$ & $39(97.4)$ \\
Chloramphenicol & $2(8)$ & $23(92)$ & & $1(2.5)$ & $39(97.5)$ \\
Ciprofloxacin & $23(88)$ & $2(8)$ & & $27(67.5)$ & $13(32.5)$ \\
Clotrimazole & $20(80)$ & $5(20)$ & & $27(67.5)$ & $13(32.5)$ \\
Cloxacillin & $25(100)$ & - & & - & $40(100)$ \\
Doxycycline & $4(16)$ & $21(84)$ & & $1(2.5)$ & $39(97.5)$ \\
Gentamicin & $6(24)$ & $19(76)$ & & $8(20)$ & $32(80)$ \\
Erythromycin & $16(60)$ & $10(40)$ & & $14(35)$ & $26(65)$ \\
Linezolid & - & $25(100)$ & & - & $40(100)$ \\
Vancomycin & - & $25(100)$ & & - & - \\
Tetracycline & - & $25(100)$ & - & - \\
Tigecycline & - & $25(100)$ & - & - \\
\hline
\end{tabular}

${ }^{*}$ R: Resistant, *S: Sensitive, MRSA: Methicillin-resistant Staphylococcus aureus, MSSA: Methicillin-sensitive Staphylococcus aureus

Table 5: Rate of MRSA in different chemical samples

\begin{tabular}{llll}
\hline $\begin{array}{l}\text { Type of } \\
\text { sample }\end{array}$ & $\begin{array}{l}\text { Number of } \\
\text { Staphylococcus aureus }\end{array}$ & $\begin{array}{l}\text { Methicillin } \\
\text { susceptibility }\end{array}$ \\
\cline { 3 - 4 } & & MRSA (\%) & MSSA (\%) \\
\hline Blood & 1 & $1(100)$ & - \\
$\begin{array}{l}\text { Invasive } \\
\text { devices }\end{array}$ & 1 & $1(100)$ & - \\
Pus/wound & 59 & $22(37.29)$ & $37(62.72)$ \\
Swab & & & \\
Swab & 3 & - & $3(100)$ \\
Tissue & 1 & $1(100)$ & - \\
Total & 65 & $25(38.46)$ & $40(61.54)$ \\
\hline
\end{tabular}

MRSA: Methicillin-resistant Staphylococcus aureus, MSSA: Methicillin-sensitive Staphylococcus aureus

Table 6: Distribution of MRSA and MSSA in outpatients

\begin{tabular}{lllll}
\hline $\begin{array}{l}\text { Patients } \\
\text { type }\end{array}$ & $\begin{array}{l}\text { Number of } \\
\text { MRSA (\%) }\end{array}$ & $\begin{array}{l}\text { Number of } \\
\text { MSSA (\%) }\end{array}$ & $\begin{array}{l}\text { Total } \\
\text { number (\%) }\end{array}$ & p-value \\
\hline Inpatients & $11(61.11)$ & $7(38.88)$ & $18(27.692)$ & $<0.05$ \\
Outpatients & $14(29.78)$ & $33(70.21)$ & $47(72.307)$ & \\
Total & $25(38.46)$ & $40(61.59)$ & $65(100)$ & \\
\hline
\end{tabular}

MRSA: Methicillin-resistant Staphylococcus aureus, MSSA: Methicillin-sensitive Staphylococcus aureus

Table 7: Gender-wise distribution of MRSA in outpatients and inpatients

\begin{tabular}{lllll}
\hline \multirow{2}{*}{ Gender } & MRSA & \multicolumn{2}{c}{ Total (\%) } & p-value \\
\cline { 2 - 3 } & Outpatients (\%) & Inpatients (\%) & \\
\hline Male & $12(63.15)$ & $7(36.85)$ & $19(76)$ & $>0.05$ \\
Female & $2(33.33)$ & $4(66.67)$ & $6(24)$ & \\
Total & $14(56)$ & $11(44)$ & $25(100)$ & \\
\hline
\end{tabular}


Table 8: Distribution frequency of biofilm formation by TCP and CRA

\begin{tabular}{llllll}
\hline TCP method & Frequency & Percentage & CRA & Frequency & Percentage \\
\hline Strong & 2 & 3.07 & Positive & 25 & 38.46 \\
Moderate & 7 & 10.76 & Negative & 40 & 61.53 \\
Weak & 43 & 66.15 & & & \\
Non-biofilm & 13 & 20.0 & & 65 & 100.0 \\
Total & 65 & 100.0 & & \\
\hline
\end{tabular}

CRA: Congo red agar, TCP: Tissue culture plate

Whereas, remaining 13 (20\%) were identified as non-adherent. The details are presented in Table 8.

\section{Sensitivity and specificity of CRA method}

The TCP method was considered as the gold standard method for this study and was compared with the results from CRA. The sensitivity and specificity of CRA were found to be $58.13 \%$ and $76.47 \%$, respectively.

\section{Rate of biofilm producer in different clinical samples}

The number of biofilm producers and non-producer out of $65 \mathrm{~S}$. aureus isolates was $52(80 \%)$ and $13(20 \%)$, respectively. The high no. of biofilm producers was obtained from the pus/wound $(n=49$, i.e., $83.05 \%)$, followed by invasive devices, swab, and tissue $(n=1$, i.e., $33.33 \%$ ), as presented in Table 9.

Distribution frequency of biofilm in outpatients and inpatients Among 65, S. aureus isolates, 16 (88.89\%) and 36 (75.59\%) were biofilm producers obtained from inpatients and outpatients, respectively. A higher number of biofilm producers was obtained from inpatients but there was no statistical significance as shown in Table 10.

The contrast of antimicrobial resistance pattern among biofilm producer and non-producer

Strong biofilm producer was relatively more resistant to tested antibiotics compared to non-biofilm producer with Linezolid as an exception, which was detected to be the most effective antibiotic to both biofilm producer and non-producer as presented in Table 11.

\section{Correlation between biofilm and MRSA}

Microtiter plate assay used for assessing bacterial attachment, that is, biofilm from the MRSA resulted in $30.7 \%$ positive biofilm producer whereas, $69.23 \%$ were obtained from MSSA. Out of 25 MRSA, 16 (64\%) were biofilm producers, and 9 (36\%) non-biofilm producers which facilitate no significant association between methicillin-resistant and biofilm production as shown in Table 12.

\section{MIC of oxacillin}

The MIC value of oxacillin for $S$. aureus ranged from $0.025 \mu \mathrm{g} / \mathrm{mL}$ to $128 \mu \mathrm{g} / \mathrm{mL}$. The $20(30.76 \%)$ of $S$. aureus were detected to be MRSA out of 65 isolates by agar diffusion method with cutoff value $4 \mu \mathrm{g} / \mathrm{mL}$, of which $3(15 \%)$ isolates had a MIC of $128 \mu \mathrm{g} / \mathrm{mL}$ (high-level oxacillin resistant). Those isolates, $\mathrm{n}=5$ which were MRSA by cefoxitin disk diffusion method but MSSA by oxacillin in MIC method had MIC value of $2 \mu \mathrm{g} / \mathrm{mL}, 1 \mu \mathrm{g} / \mathrm{mL}$ as shown in Table 13 .

S. aureus, a common human microbiota, whose emergence of antibioticresistant strain adept of causing minacious health issues [19]. The present study was performed at Kathmandu Model Hospital.

In this study, 3388 clinical samples were collected and processed, of which $604(17.02 \%)$ and 2784 (82.98\%) displayed positive and negative growth, respectively. Among positive samples analyzed, $462(19.6 \%)$ and $142(24.8 \%)$ were from outpatients and inpatients, respectively, which is analogous to the (Iregbu et al., 2013) [20]. Similarly, $576(95.60 \%)$ of total 604 culture-positive showed monomicrobial growth of which 126 (20.86\%) were Gram-positive that allied with (Garcia-Granja et al., 2015), resulting in 821 (81.2\%) as monomicrobial [21].
Table 9: Rate of biofilm producer in different clinical samples

\begin{tabular}{|c|c|c|c|c|}
\hline \multirow{2}{*}{$\begin{array}{l}\text { Type of } \\
\text { sample }\end{array}$} & \multirow{2}{*}{$\begin{array}{l}\text { Number } \\
\text { of isolates }\end{array}$} & \multicolumn{2}{|c|}{ Positive/Negative } & \multirow[t]{2}{*}{ Total (\%) } \\
\hline & & $\begin{array}{l}\text { Producer } \\
(\%)\end{array}$ & $\begin{array}{l}\text { Non-producer } \\
(\%)\end{array}$ & \\
\hline Blood & 1 & - & $1(100)$ & 1 \\
\hline $\begin{array}{l}\text { Invasive } \\
\text { devices }\end{array}$ & 1 & $1(100)$ & - & 1 \\
\hline Pus/wound & 59 & 49 (83.5) & $10(16.95)$ & 59 \\
\hline Swab & 3 & $1(33.3)$ & $2(66.66)$ & 3 \\
\hline Tissue & 1 & $1(100)$ & - & - \\
\hline Total & 65 & $52(80)$ & $13(20)$ & 65 (100) \\
\hline
\end{tabular}

Table 10: Distribution frequency of biofilm in inpatients and outpatients

\begin{tabular}{|c|c|c|c|c|}
\hline \multirow{2}{*}{$\begin{array}{l}\text { Type of } \\
\text { patients }\end{array}$} & \multicolumn{2}{|c|}{ Positive/Negative } & \multirow[t]{2}{*}{ Total (\%) } & \multirow[t]{2}{*}{ p-value } \\
\hline & $\begin{array}{l}\text { Biofilm } \\
\text { producer (\%) }\end{array}$ & $\begin{array}{l}\text { Non-biofilm } \\
\text { producer }(\%)\end{array}$ & & \\
\hline Inpatients & 16 (88.89) & $2(11.11)$ & 18 (27.69) & $>0.05$ \\
\hline Outpatients & 36 (76.59) & $11(23.40)$ & 47 (72.31) & \\
\hline Total & $52(80)$ & $13(20)$ & $65(100)$ & \\
\hline
\end{tabular}

Out of 126 Gram positive bacterial isolates, 65 (51.58\%), 44 (34.92\%), and $17(13.49 \%)$ were S. aureus, CoNS, and non-staphylococcal respectively. Furthermore, a maximum number of $S$. aureus and MRSA were isolated from pus/wound swab (22/59), followed by invasive devices, blood that allied with the result of (Pandey et al., 2012) ascertaining the role of organisms as a cause of pyogenic infection [22].

Male patients $(63.07 \%)$ displayed a higher frequency of S. aureus infection than female patients (36.92\%) on the gender-wise distribution of a total of 53 isolates which incident with the findings of (Shahina et al., 2014), 60.65\%, 39.35\% in male and females, respectively [23]. The maximum number of patients infected belonged to the age group of 21-30 in both genders, which was consistent with the finding of (Bhandari et al., 2019) [24].

In this study, the most effective antibiotic against $S$. aureus was Linezolid with $100 \%$ sensitivity in both MRSA and MSSA which following the study conducted by (Belbase et al., 2017) and (Moghadam et al., 2014) [25,17]. MRSA strains were more resistant to all tested antibiotics than MSSA. The increased resistance of MRSA to a multitude of antibiotics is probably due to irrational and inappropriate use of antimicrobial agents, disregard to hospital infection control policies showing negligible regard to culture susceptibility pattern while administrating antimicrobial agents [26].

The prevalence of MRSA infection was found to be $38.46 \%$ agreeing with (Adhikari et al., 2017) but lower, that is, $26.12 \%$ in (Pandey et al., 2012) also, higher that is, $69.1 \%$ in (Tiwari et al., 2014) [22,27,28]. The variation might be due to variation in antibiotics usage and infection control in various places, patients, and clinical specimens [29].

Although S. aureus occurrence was higher in outpatients, MRSA isolates were significantly associated $(\mathrm{p}>0.05)$ with inpatients $(61.1 \%)$ 
Table 11: Relative comparison of antimicrobial resistance pattern among biofilm producer and non-producer

\begin{tabular}{|c|c|c|c|c|}
\hline \multirow[t]{2}{*}{ Antibiotics } & \multicolumn{4}{|c|}{ The resistant pattern of biofilm producer and non-producer } \\
\hline & Strong $(n=2)(\%)$ & Moderate $(n=7)(\%)$ & Weak $(n=43)(\%)$ & Non-producer (\%) \\
\hline Penicillin-G & $2(100)$ & $6(85.33)$ & $40(93.02)$ & $10(76.92)$ \\
\hline Amoxiclav & $2(100)$ & $3(42.85)$ & $29(67.74)$ & $10(76.92)$ \\
\hline Cefoxitin & $2(100)$ & $4(57.14)$ & $9(20.93)$ & $9(69.23)$ \\
\hline Cephalexin & $1(50)$ & $3(42.85)$ & $2(4.65)$ & $1(7.69)$ \\
\hline Chloramphenicol & $1(50)$ & - & $1(2.32)$ & $1(7.69)$ \\
\hline Ciprofloxacin & $2(100)$ & $4(71.42)$ & $30(69.76)$ & $11(84.61)$ \\
\hline Clotrimazole & $1(50)$ & $2(42.85)$ & $22(51.63)$ & $9(69.23)$ \\
\hline Cloxacillin & $2(100)$ & $4(57.14)$ & $10(23.25)$ & $9(69.23)$ \\
\hline Doxycycline & $1(50)$ & $2(28.57)$ & $2(4.65)$ & - \\
\hline Erythromycin & $1(50)$ & $3(42.85)$ & $12(27.91)$ & $9(69.23)$ \\
\hline Gentamycin & $1(50)$ & $2(28.57)$ & $3(6.97)$ & $3(23.07)$ \\
\hline Linezolid & 0 & 0 & 0 & 0 \\
\hline
\end{tabular}

Table 12: Relation of methicillin-resistant and biofilm production

\begin{tabular}{lll}
\hline Biofilm (Microtiter plate assay) & Methicillin susceptibility & Total (\%) \\
\cline { 2 - 3 } & MRSA (\%) & MSSA (\%) \\
\hline Producer & $16(30.7)$ & $36(69.23)$ \\
Non-producer & $9(69.23)$ & $4(30.7)$ \\
Total & $25(38.46)$ & $40(61.53)$ \\
\hline
\end{tabular}

MRSA: Methicillin-resistant Staphylococcus aureus, MSSA: Methicillin-sensitive Staphylococcus aureus

Table 13: Minimum inhibitory concentration value of oxacillin

\begin{tabular}{|c|c|c|c|c|c|c|c|c|c|c|}
\hline Concentration of oxacillin $(\mu \mathrm{g} / \mathrm{mL})$ & 0.25 & 0.5 & 1.0 & 2.0 & 4.0 & 8.0 & 16.0 & 32.0 & 64.0 & 128 \\
\hline Number of isolates & 1 (ATCC) Staphylococcus aureus & 15 & 20 & 10 & 6 & 4 & 2 & 3 & 2 & 3 \\
\hline
\end{tabular}

compared to outpatients (29.87\%), which allied with the findings of (Ansari et al., 2014), that is, $66.9 \%$ and $33.1 \%$ as outpatients and inpatients, respectively. This difference could be due to prolonged hospital stay, instrumentation, and other invasive devices, also S. aureus is a major organism causing nosocomial infections.

A wide variety of microorganisms are capable of developing biofilm. Since, there is no standard protocol for biofilm detection, the most widely used assay for evaluation is the microtiter plate assay (Moghadam et al., 2014). In this study, the TCP method and CRA method were used.

TCP, the standard method, detected $53(80 \%)$ as S. aureus producing biofilm agreeing with (Mohamed et al., 2016) as 78\% producing biofilm. Out of 65 isolates, $2(3.07 \%)$ were strongly adherent, 7 (10.76\%) moderately, weakly 44 (67.69\%), and $13(20 \%)$ non-adherent and were comparable with (Ghellai et al., 2014), who found that 4 (8\%) were strongly adherent, 10 (20\%) moderately, 20 (40\%) weakly, and 16 (32\%) non-adherent [30].

CRA, the phenotypic method detected 25 (38.46\%) and 40 (61.54\%) as biofilm producer and non-producer, respectively, that coincides with the finding of (Mohamed et al., 2016), that is, $56.8 \%$ as positive biofilm producer [31]. However, (Mathur et al., 2006), reported a lesser number of biofilm production, which may be due to the imprecision in the identification of moderate biofilm-producing strains by this method (Hassan et al., 2011) [4,32].

In this study, the majority of biofilm-producing bacteria were isolated from pus/wound, followed by invasive devices and tissue [33]. Furthermore, a maximum number of biofilm producers was obtained from inpatients $(88.89 \%)$ than outpatients $(76.59 \%)$, which was statistically insignificant.

Higher rates of drug resistance were found among strong biofilmproducing strains in comparison to biofilm non-producing strains. These findings were in favor of results reported by (Belbase et al., 2017).
Due to the protective nature of biofilm, bacteria growing in it are intrinsically resistant to many antibiotics. Positive biofilm producer was $30.7 \%$ in the samples obtained from the MRSA and $69.23 \%$ obtained from MSSA. There is no statistical association between methicillin-resistant and biofilm production. In a study conducted by (Grinholc et al., 2007), among all tested strains, only $45-47 \%$ of MRSA and $66-69 \%$ of MSSA strains were to produce biofilm in vitro. It has been reported that some strains, despite the presence of a locus do no produce biofilm [34].

Both cefoxitin disk diffusion method and oxacillin agar dilution method were performed for the detection of MRSA. In this study, 38.46\% isolates were found MRSA by cefoxitin disk diffusion method and $30.78 \%$ isolates were found MRSA by oxacillin agar dilution method. In a study conducted by (Adhikari et al., 2017), 35.50\% and 31.82\% were identified as MRSA by cefoxitin disk diffusion method and oxacillin micro-dilution method.

Those isolates with $\mathrm{n}=5$ were MRSA by cefoxitin disk diffusion method but MSSA by oxacillin MIC method had MIC value of $2 \mu \mathrm{g} / \mathrm{mL}$, $1 \mu \mathrm{g} / \mathrm{mL}$, respectively, allied with the study conducted by (Adhikari et al., 2017) [27].

\section{CONCLUSION}

The prevalence rate of isolation of MRSA from hospitalized patients of Staphylococcus positive cases was found to be high. The pus/wound was the main source of $S$. aureus and MRSA in hospital settings. The findings of the study on gender-based evaluation displayed a higher frequency of MRSA in male patients compared to female patients between the age group of 20 and 29 years. For the treatment of $S$. aureus infection including MRSA linezolid (100\%) was the drug of choice followed by chloramphenicol (92\%), doxycycline (84\%), and gentamicin (76\%). MRSA strains displayed multidrug-resistant properties and were unusually resistant even to Vancomycin, the drug of choice, which means the emergence of MRSA is dynamic. Hence, reducing this threat 
by practicing good infection control policies, performing regular surveillance of the antibiotics profile of Staphylococcus isolates to formulate antibiotic policies, and prudent use of antimicrobial agents is recommended. Furthermore, genotypic studies of resistant strains of S. aureus seem vital.

\section{ACKNOWLEDGMENTS}

The authors would like to thank the Department of Microbiology and Department of Chemistry, Tri-Chandra Multiple Campus, Tribhuvan University, Kathmandu, Nepal, for technical support. Thanks also go to Kathmandu Model Hospital, Pardarsanimarg, Kathmandu, Nepal, for laboratory facilities.

\section{AUTHORS CONTRIBUTIONS}

All authors have almost equal contributions in this work as well as in the manuscript preparation.

\section{CONFLICT OF INTREST}

The authors declare that they have no conflict of interest.

\section{AUTHORS FUNDING}

There is no funding for authors to carry out this research work but laboratory facilities were provided by Kathmandu Model Hospital, Department of Microbiology, and Department of Chemistry, Tri-Chandra Multiple Campus, Tribhuvan University, Kathmandu, Nepal.

\section{REFERENCES}

1. Stapleton PD, Taylor PW. Methicillin resistance in Staphylococcus aureus: Mechanism and modulation. Sci Prog 2002;85:57-72.

2. Pozzi C, Waters EM, Rudkin JK, Lohan AM, Tong P, Loftus BJ, et al. Methicillin resistance alters the biofilm phenotype and attenuates virulences in S. aureus device-associated infections. PLoS Pathog 2012;8:e1002626.

3. Thammanvongsa V, Kim HK, Missiakleas D, Scheewmd O. Staphylococcal manipulation of host immune responses. Nature Rev Microbiol 2015:13:529-43.

4. Mathur T, Singhal S, Khan S, Upadhay DJ, Fatma T, Rattan A. Detection of biofilm formation among the clinical isolates of staphylococci: An evaluation of three different screening methods. Indian J Med Microbiol 2006;24:25-9.

5. Ziebhur W, Lobner I, Krimmer V, Hacker J. Methods to detect and analyze phenotypic variation in biofilm-forming staphylococci. Method Enzymol 2001;336:195-233.

6. Houston P, Rowe SE, Pozzi R, Water EM, Gara JP. Essential role for the major autolysin in the fibronectin-binding protein-mediated Staphylococcus aureus biofilm phenotype. Infect Immun 2011;79:1153-65.

7. Altieri KT, Sanita PV, Machado AL, Giampaolo ET, Pavarina AC, Jorge JH, et al. Eradication of mature methicillin-resistant Staphylococcus aureus (MRSA) biofilm from acrylic surfaces. Braz Dent J 2013;24:487-91.

8. Hadler JL, Petit S, Mandour M, Cartter ML. Trend in invasive infection with methicillin-resistant Staphylococcus aureus, Connecticut, USA, 2001-2010. Emerg Infect Dis 2012;18:917-24.

9. Gould IM. The clinical significance of methicillin-resistant Staphylococcus aureus. J Hosp Infect 2005;61:272-82.

10. Ansari S, Nepal HP, Gautam R, Rayamajhi N, Shrestha S, Upadhyay G, et al. Threat of drug-resistant Staphylococcus aureus to health in Nepal. Biomed Cent Infect Dis 2014;14:157.

11. Wolcott RD, Ehrlich GD. Biofilm and chronic infections. J Am Med Assoc 2008;299:2682-4.

12. Enright MC. The evolution of a resistant pathogen-the case of MRSA. Curr Opin Pharmacol 2003;3:474-9.

13. Hidron Al, Kourbatova EV, Halvosa JS, Terrell BJ, McDougal LK, Tenover FC, et al. Risk factors for colonization with methicillinresistant Staphylococcus aureus (MRSA) in patients admitted to Urban hospital: Emergence of community-associated MRSA nasal carriage. Clin Infect Dis 2005;41:159-66.

14. Collee JF, Fraser AG, Marmion BO, Simmons A. Staphylococcus: Cluster forming gram positive cocci. In: Mackie and McCartney
Practical Medical Microbiology. $14^{\text {th }}$ ed. United States: Churchill Livingstone; 2006

15. Cheesebrough M. District Laboratory Practice in Tropical Countries Part 2. Cambridge, England: Cambridge University Press; 2006.

16. Clinical and Laboratory Standards Institute. CLSI Performance Standards for Antimicrobial Susceptibility Testing, Twenty-fourth Supplement, CLSI Document M100-S24. Wayne, PA: Clinical and Laboratory Standards Institute; 2014.

17. Moghadam SO, Pourmad MR, Aminharati F. Biofilm formation and antimicrobial resistance in methicillin-resistant Staphylococcus aureus isolated from burn patients, Iran. J Infect Dev Countries 2014;8:1511-7.

18. Kwasny SM, Opperman JT. Static biofilm cultures of gram-positive pathogens grown in microtiter format used for anti-biofilm drug discovery. Curr Protoc Pharmacol 2010;50:13A.8.

19. Kshetry AO, Pant ND, Khatri S, Shrestha KL, Upadhaya SK, Poudel A, et al. Minimum inhibitory concentration of vancomycin to methicillinresistant Staphylococcus aureus isolated from different clinical samples at a tertiary care hospital in Nepal. Antimicrob Resist Infect Control 2016;5:27.

20. Iregbu KC, Uwaezuoke NS, Nwajiobi-Princewill IP, Eze SO, Medugu N, Shettima S, et al. A profile of wound infection in national hospital Abuja. Afr J Clin Exp Microbiol 2013;14:160-3.

21. Garcia-Granja PE, López J, Vilacosta I, Ortiz-Bautista C, Sevilla T, Olmos C, et al. Polymicrobial infective endocarditis: Clinical features and prognosis. Medicine 2015;94:1-6.

22. Pandey S, Raza S, Bhatta CP. Prevalence and antibiotic sensitivity pattern of methicillin-resistant Staphylococcus aureus in Kathmandu medical college-Teaching hospital. J Inst Med 2012;34:13-7.

23. Shahina Z, Chowdhury AH, Arifuzzaman MD. Prevalence of antimicrobial sensitivity and resistant pattern of a gram-positive cluster forming cocci in clinical samples. IOSR J Dent Med Sci 2014;13:53-7.

24. Bhandari G, Pokharel B, Oli Y, Katuwal A, Bhandari NL. Screening of methicillin-resistant Staphylococcus aureus (MRSA) from wounds in pediatric patients visiting tertiary care in hospital. Nepal J Biotechnol 2019;7:82-9

25. Belbase A, Pant ND, Nepal K, Nepal B, Baidhya R, Lekhak B. Antibiotic resistance and biofilm production among the strains of Staphylococcus aureus isolated from pus/wound swab samples in a tertiary care hospital in Nepal. Ann Clin Microbiol Antimicrob 2017;16:2-5.

26. Verma AK, Kapoor AK, Bhargava A. Antimicrobial susceptibility pattern of bacterial isolates from surgical wound infection in tertiary care hospital in Allahabad, India. Int J Med Update 2012;7:27-34.

27. Adhikari R, Pant ND, Neupane M, Bhattarai R, Bhatta S, Chaudhary R, et al. Detection of methicillin-resistant Staphylococcus aureus and determination of the minimum inhibitory concentration of vancomycin for Staphylococcus aureus isolated from pus/wound samples of the patients attending a tertiary care hospital in Kathmandu Nepal. Can J Infect Dis Med Microbiol 2017:1-6.

28. Tiwari HK, Das AK, Sapkota D, Sivarjan K, Pahwa VK. Methicillinresistant Staphylococcus aureus prevalence and antibiogram in tertiary care hospital in Western Nepal. J Infect Dev Ctries 2009;3:681-4.

29. Goyal A, Diwakar MK, Bhosshan S, Goyal S, Agrawal A. Prevalence and antimicrobial susceptibility pattern of methicillin-resistant Staphylococcus aureus (MRSA) isolates at a tertiary care hospital in Agra, North India-a systemic annual review. IOSR J Dent Med Sci 2013;11:80-4.

30. Ghellai L, Hassaine H, Klouche N, Khadir A, Aissaoui N, Nas F, et al. Detection of biofilm formation of a collection of fifty strains of Staphylococcus aureus isolated in Algeria at the university hospital of Telmcan. J Bacterio Rese 2014;6:1-6.

31. Mohamed A, Rajaa AM, Khalid Z, Fouad M, Naima R. Comparison of three methods for the detection of biofilm formation by clinical isolates of S. aureus isolated in Casablanca. Int J Sci Rese 2016;5:1156-9.

32. Hassan A, Usman J, Kaleen F, Omkar M, Khalid A, Iqbal M. Evaluation of different detection methods of biofilm formation in the clinical isolates. Braz J Infect Dis 2011;15:305-11.

33. Devaraj C, Sajjan GA. Comparison of three different methods for detection of biofilm in gram-positive cocci and gram-negative Bacilli isolated from clinical specimens. J Pharm Sci Rese 2015:7:952-5.

34. Grinholc M, Wegryn G, Kurlend J. Evaluation of biofilm production and prevalence of the icaD gene in methicillin-resistant and methicillinsusceptible Staphylococcus aureus strains isolated from patients with nosocomial infections and carrier. FEMS Immun Med Microbiol 2007;50:375-9. 